\title{
EXPERIÊNCIA COLABORATIVA DE FORMAÇÃO CONTINUADA DE PROFESSORES DE EDUCAÇÃO FÍSICA: UM ESTUDO INTERPRE- TATIVO
}

\author{
Bruno Vasconcellos Silva \\ Universidade Federal do Espírito Santo, Vitória, Espírito Santo, Brasil. \\ Zenólia Christina Campos Figueiredo \\ Universidade Federal do Espírito Santo, Vitória, Espírito Santo, Brasil. \\ Cláudia Aleixo Alves \\ Universidade Federal do Espírito Santo, Vitória, Espírito Santo, Brasil.
}

\begin{abstract}
Resumo:
O estudo apresenta a interpretação e avaliação de professores de Educação Física acerca de uma experiência de formação continuada. O estudo é interpretativo, com aproximação ao campo empírico, por meio da observação participante, entrevistas semiestruturadas e diário de campo. As interpretações dessa experiência nos permitem avaliar que dela emergem o que denominamos de princípios orientadores do processo formativo, a saber: a) trabalho coletivo e colaborativo; b) saberes e trocas de experiências dos professores; c) ratificação de que os docentes sejam atores e autores do processo; e d) sugestão para aproximações entre as discussões acadêmicas e o "chão da escola".
\end{abstract}

Palavras-chave: Formação continuada. Experiência. Educação Física.

\section{COLLABORATIVE EXPERIENCE OF CONTINUING EDUCATION OF PHYSICAL EDUCATION TEACHERS: AN INTERPRETIVE STUDY}

\begin{abstract}
:
The study presents the interpretation and evaluation of physical education teachers about a continuing education experience. The study is interpretive, with approximation to the empirical field, through participant observation, semistructured interviews and field diary. The interpretations of this formative experience allow us to evaluate the emergence of what we call the guiding principles of the formative process, namely: a) collective and collaborative work; b) knowledge and exchange of teachers' experiences; c) ratification of teachers being actors and authors of the process; and d) suggestion for approximations between academic discussions and the "school floor".
\end{abstract}

Keywords: Continuing education. Experience. Physical education.

\section{EXPERIENCIA COLABORATIVA DE FORMACIÓN CONTINUADA DE PROFE- SORES DE EDUCACIÓN FÍSICA: UN ESTUDIO INTERPRETATIVO}

\section{Resúmen:}

El estudio presenta la interpretación y evaluación de profesores de educación física acerca de una experiencia de formación continuada. El estudio es interpretativo, con aproximación al 
campo empírico, por medio de la observación participante, entrevistas semiestructuradas y diario de campo. Las interpretaciones de esta experiencia formativa nos permiten evaluar que emergen lo que denominamos principios orientadores del proceso formativo, a saber: a) trabajo colectivo y colaborativo; b) saberes e intercambios de experiencias de los profesores; c) ratificación de que los docentes sean actores y autores del proceso; y d) sugerencia para aproximar las discusiones académicas y el "espacio de la escuela".

Palabras clave: Formación continua. La experiencia. Educación física.

\section{Introdução}

Este $\operatorname{artigo~}^{1}$, fruto de uma dissertação de mestrado ${ }^{2}$, trata de avaliar uma experiência de formação continuada de professores de Educação Física que atuam no ensino fundamental (do $1^{\circ}$ ao $9^{\circ}$ ano) na Rede Municipal de Ensino da Grande Vitória-ES ${ }^{3}$. Essa formação, desenvolvida no ano de 2015, foi mediada pelo pesquisador do estudo que também é professor efetivo da referida Rede de Ensino, sendo esta subsidiada pelos princípios da reconstrução coletiva e colaborativa.

Entendemos que avaliar é refletir permanentemente sobre as finalidades e os objetivos do que vem sendo experimentado no cotidiano (SACRISTÁN, 1998). Dado isso, intentamos analisar e valorizar as particularidades e as condições formativas dos processos de formação inicial e continuada dos professores em exercício na Educação Básica. Neste artigo, portanto, a formação continuada de professores de Educação Física é nosso foco.

Tal perspectiva de avaliação compreende a realidade como complexa, dinâmica, aberta e polissêmica. A avaliação pode organizar o conjunto de ideias, ações, estruturas e relações, com o objetivo de compreender e qualificar as instituições educativas de maneira coletiva (DIAS SOBRINHO, 2003, 2004).

Experiências são compreendidas como algo marcante em nossa trajetória. Um momento que se constitui como uma memória viva e cristalina, algo que passa por nossa trajetória e promove aprendizado e reflexão. Nos dizeres de Larrosa Bondía (2002):

A experiência é o que nos passa, o que nos acontece, o que nos toca. Não o que se passa, não o que acontece, ou o que toca. A cada dia se passam muitas coisas, porém, ao mesmo tempo, quase nada nos acontece. Dir-se-ia que tudo o que se passa está organizado para que nada nos aconteça. (BONDÍA, 2002, p. 21)

Sendo assim, a experiência é singular, produtora de diferenças/pluralidades/heterogeneidades, irrepetível, incerta e não pode ser um caminho para o objetivo previsto ou uma meta conhecida de antemão, mas é uma abertura para o desconhecido, para o que não se pode antecipar (BONDÍA, 2002).

A experiência avaliada não se restringiu a um individualismo e voluntarismo por parte do professorado. Partimos do pressuposto de que o conhecimento do professor pode ser desenvolvido no processo de formação continuada para promover capacidades reflexivas coletivas sobre a própria prática docente, bem como contribuir para aprender a interpretar, compreender e refletir sobre a educação e a realidade social de maneira comunitária, desenvolvida com a ajuda dos pares (IMBERNÓN, 2000).

$1 \mathrm{O}$ presente trabalho não contou com apoio financeiro de nenhuma natureza para sua realização.

2 Pesquisa aprovada pelo Comitê de Ética e Pesquisa, da Universidade Federal do Espírito Santo - Campus de Goiabeiras. CAAE: 64032516.1.0000.5542. Número do Parecer: 2.182.134.

3 A Região Metropolitana da Grande Vitória, do Estado do Espírito Santo, é composta pelos municípios: Cariacica, Fundão, Guarapari, Serra, Viana, Vila Velha e Vitória. 
Desse modo, optamos por fazer um recorte da pesquisa desenvolvida e apresentar neste artigo a interpretação e avaliação dos docentes do que foi perspectivado e efetivamente realizado na referida experiência formativa. Ressaltamos a importância de analisar o empírico e desenvolver a crítica teórica a partir da avaliação, refletida no coletivo, quando os próprios agentes da instituição se assumem como protagonistas da tarefa (DIAS SOBRINHO, 2003, 2004).

\section{Estudo interpretativo da experiência}

Este estudo é interpretativo, com aproximação ao campo empírico, por meio da observação participante, entrevistas semiestruturadas ${ }^{4}$ e diário de campo. $\mathrm{O}$ trabalho de campo se caracterizou, marcadamente, por uma interação social entre o pesquisador - professor/mediador dos encontros - e os sujeitos participantes da pesquisa - professores de Educação Física da Rede de Ensino.

Apoiamo-nos em Sarmento (2011), que referencia o paradigma interpretativo em estudos sociais e organizacionais, no qual o trabalho relacional pode ser uma das condições para a interpretação científica. $\mathrm{O}$ autor endossa que interpretar a ação e sua simbolização pelos atores sociais no contexto pode ser a síntese de uma perspectiva que se revê no quadro do paradigma interpretativo. Logo, avaliar o entendimento docente de uma experiência de formação continuada, também nos parece que pode ser correlacionada a tal paradigma.

A Rede de Ensino investigada ofertou à população, no período diurno de 2015, um total de 68 unidades escolares com ensino fundamental. São 31 Escolas Municipais de Ensino Fundamental (Emefs) que oferecem somente o ensino fundamental do $1^{\circ}$ ao $5^{\circ}$ ano, 22 Emefs que abrangem todo o fundamental, ou seja, do $1^{\circ}$ ao $9^{\circ}$ ano, 6 Emefs que atendem somente do $6^{\circ}$ ao $9^{\circ}$ ano, bem como 9 Centros Municipais de Educação Infantil que oferecem turmas de $1^{\circ}$ ano do ensino fundamental.

As condições de trabalho vivenciadas pelos professores em atuação nas escolas da referida Rede não diferem, consubstancialmente, da realidade enfrentada pela maioria dos educadores brasileiros, com grande parte de seus profissionais lecionando em dois ou até três turnos de trabalho, desenvolvendo suas práticas no decorrer das aulas com número significativo de estudantes e em espaços/tempos, muitas vezes, com escassez de recursos didáticos/pedagógicos.

A escolha dos docentes envolvidos na experiência foi por designação, visto que, além dos professores estatutários, havia os contratados por determinação temporária (DT) que ingressaram na Rede de Ensino via processo seletivo. O quadro docente da disciplina Educação Física era composto, inicialmente, por 105 professores (incluindo o mediador). Havia 55 pro-

4 Os critérios para escolha dos professores de Educação Física que entrevistamos foram: a) ao menos três docentes que tenham se envolvido em todo o processo da experiência de formação continuada daquele ano, contando a frequência desejável nos encontros presenciais, nos quais tenham demonstrado interesse e envolvimento nas atividades propostas, tenham entregado o trabalho escrito, participado na plataforma moodle e apresentado seus relatos de experiência no seminário de práticas; b) ao menos três professores que tenham se envolvido na experiência de formação continuada, contando a frequência desejável nos encontros presenciais, tenham demonstrado interesse e envolvimento nas atividades propostas, contudo não participaram da plataforma moodle e/ou não apresentaram seus trabalhos no seminário; c) ao menos três docentes que não tenham se envolvido significativamente no decorrer da experiência da formação continuada, ou seja, participando dos encontros presenciais, contudo não demonstrando grande interesse e envolvimento nas atividades propostas, não tenham entregado trabalhos escritos, nem tenham participado do moodle ou apresentado trabalho no seminário; e d) todos os entrevistados deveriam ter participado dos processos de formação continuada da Rede nos anos de 2013 e 2014, visto que o processo formativo de 2015 foi uma continuidade desses. Assim, tendo em vista a esses critérios para escolha dos professores, pareceu-nos interessante entrevistar atores que se envolveram de diferentes maneiras nessa experiência de formação continuada, de modo que possam contribuir para melhor tentarmos atingir nossa principal questão do estudo. 
fessores atuando no turno matutino, sendo 30 deles estatutários e 49 professores no vespertino, sendo 20 estatutários.

Há uma predominância de professores de Educação Física do sexo masculino, correspondente a $58,24 \%$, em detrimento do quantitativo de professoras $(41,75 \%)$. Constatamos que o tempo de serviço na Educação Básica dos docentes era variado, a saber: 23 professores lecionavam há 5 anos; 28 professores entre 6 e 10 anos; por último, identificamos 14 professores com experiências entre 11 e 15 anos. Foi curioso constatar que havia uma professora com 38 anos de tempo de serviço e outra com apenas um ano de experiência participando no mesmo turno na formação. Estas foram as professoras com o maior e o menor tempo de serviço na ocasião.

Quanto à formação acadêmica, todos são licenciados em Educação Física, haja vista que esse título é pré-requisito para ingressar, como estatutário ou contratado, na referida instituição pública. Não havia nenhum docente com título de doutor atuando na ocasião. Apenas um professor mestre. Vale ressaltar que havia $85,71 \%$ do total de professores com ao menos uma especialização lato sensu.

Iniciamos a experiência de formação continuada no dia 31 de março de 2015 e encerramos o último encontro no dia 6 de novembro do mesmo ano. Durante esse período, estivemos junto dos docentes durante todos os encontros nos turnos matutino, das 07h30min às $11 \mathrm{~h} 30 \mathrm{~min}$, e no vespertino, das $13 \mathrm{~h}$ às $17 \mathrm{~h}$. Foram realizados seis encontros durante esse período, totalizando 48 horas presenciais de formação continuada, 24 horas em cada turno. ${ }^{5}$

Promovemos uma formação continuada em que as demandas e necessidades referentes ao cotidiano fossem ouvidas e discutidas, bem como os participantes, de modo coletivo e colaborativo, contribuíssem com o processo, reconstruindo as propostas no decorrer dos encontros, valorizando o seu saber-fazer. Nessa dinâmica, o professor/mediador, por meio do diálogo, desenvolvia a formação a partir das questões/temas elencadas pelos demais professores, sendo estes responsáveis pelo desenvolvimento da experiência, contribuindo para repensá-la a cada encontro.

Destarte, o estudo interpretativo visou a avaliar essa experiência formativa, tornando o pesquisador o principal instrumento de busca das informações, tendo a fonte direta no próprio ambiente estudado, preocupando-se com o contexto, entendendo que as ações podem ser mais bem compreendidas quando são observadas no seu ambiente habitual de ocorrência (BOGDAN; BIKLEN, 1994).

Nosso trabalho não consiste em recolher fatos que, ao serem articulados, proporcionem um modo de verificar e elaborar uma teoria que estabeleça relações de causalidade e possa predizer a complexidade do comportamento humano. Por isso, nosso objetivo é melhor entender tais comportamentos e experiências. Tentamos perceber o processo, mediante ao qual, as pessoas constroem sentidos/significados para poder melhor descrever em que consistem (BOGDAN; BIKLEN, 1994).

\section{Interpretação e avaliação da experiência vivida pelos docentes na formação continuada}

Nos próximos subtópicos, enfatizamos a interpretação, respectivamente, sobre a percepção dos professores de Educação Física, participantes da experiência formativa avaliada,

\footnotetext{
5 A carga horária total da experiência da formação continuada poderia ser de até 120 horas no certificado. Assim, foram incluídos os seguintes critérios: participação presencial - correspondendo a 24 horas; apresentação de trabalho por escrito, relacionado com o planejamento do professor, quando ele descreveria mais detalhadamente o plano de ação e, se possível, registrasse com fotos as atividades e/ou mesmo os trabalhos realizados pelos discentes - correspondendo a 46 horas; apresentação de trabalhos no seminário, ou em pôster ou oral - correspondendo a 10 horas e a plataforma moodle, com a proposta de continuar os debates/discussões dos encontros presenciais via ensino a distância - correspondendo a 40 horas do certificado.
} 
do que pode ser uma formação continuada ideal e, em seguida, ajuizamos seus entendimentos sobre a experiência em voga, subsidiada pela perspectiva coletiva e colaborativa, de modo a possibilitar sua avaliação.

\title{
Os sentidos atribuídos à formação continuada pelos docentes participantes
}

Os docentes participantes dessa experiência entendem a formação continuada como possibilidade de perenidade formativa, sobretudo, quando as propostas dos encontros estão voltadas para as suas realidades, focadas em seus saberes-fazeres, promovendo mais sentido/significado em suas lidas. Esses momentos, segundo um dos docentes em resposta à entrevista $^{6}$, podem permitir uma continuidade em suas formações, constituindo-se em uma atividade contínua ao longo de sua carreira.

\begin{abstract}
Olha, conseguir fazer [a formação continuada] com que eu refletisse com temáticas, que escutassem a nós, professores, para dar mais significado e, consequentemente, contribuir no meu modo de pensar, modo de agir, modo de avaliar a realidade da escola, até atividades diversas que possam atingir nossos objetivos. Um tempo que pudesse haver um bate papo, uma troca de experiência, que pudessem nos escutar. Acho que a troca de experiência é muito válida na formação continuada. Não que viesse de cima para baixo, de fora da nossa realidade e fosse interferir, como se soubessem o que estava se passando em nossa aula. Então, que a formação possa nos dar meios para que possamos melhorar nossa realidade (EMERSON - Dados da pesquisa).
\end{abstract}

Percebemos que os docentes possuem expectativas de investimento em formações que possam contribuir na resolução dos problemas do cotidiano de suas aulas e que priorizem o diálogo com seus contextos profissionais, suas necessidades e expectativas, objetivando atender às suas demandas enquanto educadores.

A perspectiva da elaboração coletiva é destacada em detrimento da proposta verticalizada. Os docentes exaltam o seu protagonismo na condução do processo da formação continuada, sobretudo, por meio da colaboração coletiva de trocas de experiências, para melhorar suas realidades e práticas pedagógicas.

Ressaltamos a relevância das vivências/práticas nos encontros solicitada pelos pares. Para os professores, essas vivências sempre deveriam ocorrer, inclusive reforçam a relação entre teoria e prática no processo formativo, embora isso soe como um exacerbado praticismo por parte dos participantes, conforme os registros abaixo:

Então, na verdade, nós, da Educação Física, a gente gosta mesmo é da prática! Gosta, sim, de ouvir, debater, mas gosta de formações mais práticas! Formações que a gente consiga trazer para nossa realidade (PENHA - Dados da pesquisa)

Inclusive podendo falar sobre a questão das aulas práticas. Então, seria sempre interessante, na medida do possível, inserir aulas práticas, não apenas teóricas, porque isso enriquece e é uma troca de experiências (MAX - Dados da pesquisa).

O professorado denota a necessidade de que sua formação partilhe de uma proposta que busque a especificidade da Educação Física, ou seja, que haja práticas corporais, vivências práticas e mais. Associa-se à proposição de Arroyo (2000) no que se refere ao entendimento de que o saber-fazer docente é muito mais para ser vivido do que transmitido. Os professores querem se apropriar dos conteúdos e das metodologias utilizadas pelos pares, de modo a repensar seus ofícios, de acordo com seus contextos e peculiaridades.

6 Utilizamos nomes fictícios para não identificar os professores. 
Os docentes ratificam que a educação física, por sua especificidade, se diferencia das demais disciplinas escolares. Essa diferença, segundo Molina Neto (1998), deve-se ao fato de que a educação física trabalha com e através dos corpos dos estudantes. Essas particularidades são fundamentais. Basta ver suas estratégias para desenvolver e acumular conhecimentos e experiências na escola.

Charlot (2009) também defende essa especificidade da Educação Física, afirmando que ela [...] não é uma disciplina escolar 'como as demais'. E acrescentamos: felizmente. Não é igual às demais porque ela lida com uma forma do aprender que não a apropriação de "saberes enunciados". Em vez de tentar anular ou esconder essa diferença, dever-se-ia destacá-la e esclarecê-la (CHARLOT, 2009, p. 243).

Nos dizeres docentes, se o saber de que trata a Educação Física está preferencialmente associado ao fazer, o espaço/tempo da formação continuada poderia lançar seus holofotes nessa perspectiva. Assim, investigar o modo como se apropriam desse saber-fazer de ofício, bem como dos sentidos/significados que eles representam na e para a sua prática pedagógica, pode colaborar no processo formativo contínuo.

Uma possível hipótese para essa aparente resistência docente às formações mais teóricas reside no fato delas constituírem, historicamente, lugar da teoria e da capacitação e, no caso da escola, o contexto de sua aplicação. A questão não está no distanciamento dos professores quanto ao uso da teorização, do pensamento, da abstração, mas no processo histórico que delegou à formação valorizar a polarização entre teoria-prática e saber-fazer, o que, em certa medida, vem sendo apontado nos dizeres dos docentes (MOLINA NETO, 1998).

A causa da desvalorização dos saberes docentes pelas autoridades é um problema político; portanto, não epistemológico ou cognitivo. A raiz do problema encontra-se no estabelecimento da divisão do trabalho entre os que pensam, elaboram e os que aplicam e executam (TARDIF, 2000b). O professorado não deve aplicar teoria, mas reconstruir seu saber-fazer com referências de suas experiências e reflexões teóricas (CAPARROZ; BRACHT, 2007).

Avaliamos que esse tipo de formação, na qual somente se reproduz em sua lida o que se praticou, pode fomentar o fortalecimento de uma perspectiva técnico-instrumental, cujo intento é formar o professor para aplicar conteúdo, não reconhecendo suas práticas como produtoras de teoria.

Salientamos a necessidade de construir um sentido/significado de formação continuada que não esteja associado à ideia de que o professorado vivencie esses lugares para mera capacitação/treinamento/reciclagem. Contudo, é importante entendê-la como mais uma possibilidade formativa que pode promover ao docente a capacidade de problematizar sua lida cotidiana, repensá-la, bem como ser produtor de teoria. Isso implica uma mudança nas relações estabelecidas em que os professores passem de espectadores a autores e protagonistas, corresponsáveis pelo processo de formação (ARROYO, 2000).

Para tanto, tendo em vista a percepção do professorado do que parece ser uma formação continuada ideal, analisamos seus entendimentos sobre a experiência formativa em tela, subsidiada pela perspectiva coletiva e colaborativa para, assim, melhor avaliá-la.

\section{As avaliações dos docentes sobre a formação continuada: indo além do 'Ah, é tudo a mesma coisa! É só blábláblá!}

Os professores identificam uma ruptura da perspectiva posta pela Rede de Ensino a partir dos anos de 2013, 2014 e 2015, e de como a formação continuada praticada parecia dar mais sentido às práticas docentes.

Quando entrei na Rede, a formação continuada em si, em 2008, confesso que ouvia as pessoas falando: Ah, é tudo a mesma coisa! É só blábláblá! Não adianta nada! Mas, quando chegou no ano de 2013, o grupo de meninas que estavam na frente da 
formação, aí, sim, percebi que todas aquelas questões tinham mudado. E aí o trabalho delas me chamou a atenção, porque dava respostas às coisas que fazia na escola. De fato, consegui ver essa importância da formação continuada e a complementação daquilo que faço na escola, via vários relatos dos professores, vi que também eu não estava sozinha, que temos um grupo, que pensa parecido, temos as mesmas angústias dentro da área. Eu vi muitos relatos sendo feitos nas formações que ajudavam a responder a essas perguntas (SALETE - Dados da pesquisa).

Essa percepção nos fez refletir que as políticas públicas são e devem ser elaboradas como "respostas" do Estado às demandas que emergem da sociedade, bem como do próprio interior, sendo essa a expressão do compromisso público de atuação em uma determinada área a longo prazo. Contudo, os dizeres do professorado nos apontam uma política de formação continuada de mandato, que finda com a entrada do novo poder Executivo Municipal e/ou de um novo secretário de Educação Municipal, em detrimento da perspectiva de política de formação municipal (HOFLING, 2001).

A política de mandato caracteriza-se como ações políticas realizadas de maneira não corporativa e independente das instruções do grupo que elegeram determinado político, ou seja, essa perspectiva se preocupa pouco com suas raízes ideológicas, político-partidárias e com os desejos e interesses dos eleitores que a elegeram e/ou com os grupos mais necessitados que precisem dessas ações (CHAUÍ; NOGUEIRA, 2007). Já a política de Estado é constituída de acordos de longo prazo, entendida como uma ação política de continuidade, independentemente das pessoas e dos partidos que assumam os cargos políticos após os encerramentos dos mandatos (HOFLING, 2001). Essa problemática também atinge a formação continuada dos professores da Rede Pública de Ensino.

A ruptura com relação à formação é destacada, sobretudo, pelo fomento ao diálogo da Rede de Ensino com o coletivo docente. Aproxima-se da ideia das transgressões propostas por Arroyo (2000), na qual ambos, Secretaria e professorado, buscam o processo de desconstrução de estilos, culturas e práticas.

O Órgão Central passa a superar o estilo tutorial e normativo na formação, o estilo verticalizado, de cima (Rede de Ensino) para baixo (professores), possibilitando as trocas de experiências entre os pares da Rede de Ensino de acordo com suas realidades, de modo que essas vivências possam ser socializadas, discutidas e reforçadas, visando, assim, à qualidade da educação pública.

Os docentes enfatizaram a reconstrução coletiva e colaborativa da formação, apontando a continuidade com os outros anos, o diálogo com sua lida cotidiana, bem como as trocas de experiências entre os pares, sobretudo o fato de os próprios professores da Rede estarem à frente da mediação das formações.

Em 2015, achei bacana, porque as formações trouxeram mesmo as nossas necessidades. Então, assim, trouxe coisas que outro colega está trabalhando e a gente consegue ver na nossa prática. Então, em 2015, achei que as formações foram mais enriquecedoras e válidas, porque eu conseguia trazer muita coisa da formação para meu cotidiano. Lembro que já, na primeira formação, você [mediador] fez uma análise das formações dos últimos anos, você se apresentou e perguntou: o que nós esperávamos para este ano? Qual era nossa expectativa? E aquilo que nós queríamos e como queríamos que fossem os encontros. Então, teve um questionário onde você mapeou o que esperávamos que fosse e os temas que fossem debatidos ao longo do ano! E, assim, foi ao longo deste ano! Acho que a proposta conseguiu atender, sim, de algum modo atendeu a todos que ali queriam alguma coisa (PENHA - Dados da pesquisa).

O que marca a guinada do processo formativo docente da Rede, nos dizeres dos professores, é o fato de o próprio professorado assumir a função de mediar sua formação, cons- 
truindo coletivamente uma direção de dentro, socializando suas experiências e significados. Parece superar a ideia de as práticas pedagógicas serem mero ponto de chegada, algo no fim da linha para ser modificado, adotando as supostas mudanças que vêm de fora da sua lida cotidiana (ARROYO, 2000).

Avaliar o processo formativo dos professores de Educação Física por meio dessa experiência, com a própria categoria dirigente, sugere uma perspectiva de formação continuada refletida no próprio espelho, que passa a projetar sua autoimagem, por meio do caminho percorrido pelos docentes em suas realidades, sem que se pretenda dar respostas únicas e verdadeiras, mas que seja construída coletiva e colaborativamente sua formação, com o intento de melhorar sua prática pedagógica (ARROYO, 2000).

$\mathrm{O}$ professorado entende que o fato de o professor/mediador dos encontros formativos ser da Rede, participante das formações continuadas e, ainda, estar na escola atribui ao processo possibilidades de maior diálogo com suas realidades. O participante percebe que aquele que está à frente, mediando os encontros, é igual. Assim, ele passa a se ver no processo, pois a experiência de formação continuada parece refletir seu próprio espelho (ARROYO, 2000):

Foi essencial o mediador ser do município, pelo fato dele entender a realidade em que trabalha. Como você vai mediar essa relação de formação continuada entre os profissionais, se você não conhece essa realidade dos profissionais de lá? Da realidade da clientela do município? Das estruturas das escolas do município? Então, se o profissional mediador é da Rede, ele entende todas as dificuldades, facilidades e sabe que caminho tomar. Eu acho que isso facilita! (GERUZA - Dados da pesquisa).

O fato de o professor mediador ser da Rede aparece como reflexo dos professores, basta ver suas avaliações ao perceberem que se sentem iguais, que estão no mesmo patamar. Esse parece ser mais um fator que se aproxima da proposta projetada, e entendida pelos pares, sobre a horizontalização entre os envolvidos no processo formativo, visto que o mediador é conhecedor da região, do público e sofre das mesmas condições de estrutura física e materiais.

A avaliação coaduna com a projeção da elaboração coletiva e colaborativa, haja vista que endossa que a experiência de formação continuada foi dos, para e com os professores com interesses mútuos em aprender. Parece haver certa pretensão no ajuizamento do qual sua formação será de qualidade quando tiverem os holofotes focados, exclusivamente, nos saberes da experiência.

As trocas de saberes e experiências nos encontros formativos parecem colaborar com seus processos de escuta renovada, o processo de formação perene, tendo como dever de ofício a arte de diagnosticar, auscultar e perceber. A assertiva de que o saber do professor é mais para ser vivido do que transmitido, aproxima-se da sugestão dos pares que deve haver mais de um encontro sobre a mesma temática, para possibilitar mais segurança com a aproximação da realidade dos professores (ARROYO, 2000).

O professor Emerson ressaltou esse aspecto quando mencionou:

O que me toca, principalmente, é aquela [formação] onde há troca de experiências. Onde eu consigo ver aquilo sendo realizado ser possível adaptar dentro da minha realidade. Uma formação só sobre uma temática é pouco! A gente trabalha muito isso na Educação Física, desde a formação inicial, com os estágios, né?! (EMERSON - Dados da pesquisa)

Os docentes se identificam mais com as vivências/práticas na experiência de formação continuada. Além disso, no decorrer do processo, também perceberam uma interação coletiva e colaborativa entre os pares, por meio das trocas de saberes e experiências:

No decorrer das vivências, os professores juntaram-se nessas mesas em grupos, que, a priori, formaram-se por afinidade e, em seguida, os demais colegas que 'domina- 
vam' o conteúdo começaram a colaborar nas 'monitorias' ao longo da vivência ('prática'), formando-se, então, outros novos grupos cujo intento era, além de quererem aprender o jogo ou jogar, o interesse em como se ensina a jogar, perguntando detalhes de como o outro faz. Percebia-se, também, a preocupação pelo fato de não saber jogar, questionando-se se poderia conseguir ensinar. Percebia-se, de fato, uma troca de experiência entre os professores sobre a temática/conteúdo elencada (ANOTAÇÃO DE DIÁRIO DE CAMPO).

Parece que o processo formativo fomentou uma legitimação associativa do saber, não enunciado, ao fazer, caracterizado pelas trocas de saberes e experiências (CHARLOT, 2009). O professorado, ao apropriar-se dessas trocas no espaço/tempo da formação continuada, aponta as vivências/práticas como possibilidades de encontros positivos e enriquecedores, que podem promover uma busca por mais conhecimentos sobre a temática, de maneira mútua e coletiva.

Valorizar esse processo formativo, por meio do compartilhamento de saberes e experiências entre os pares, apresenta-se como possibilidade de constituir outro modo de produção de conhecimento. Não observamos um praticismo, nem postura anti-intelectual, ou mesmo sugestão de pensar um perfil docente sem domínio de conteúdo, até porque tentamos nos centralizar na experiência formativa, segundo os dizeres docentes, no como poderia apoiar-se nas teorias e matrizes pedagógicas, tendo a prática docente como um filtro para transformar o conhecimento em função das exigências da lida cotidiana (ARROYO, 2000; TARDIF, 2000a).

Aproximar-se mais de uma prática pedagogizada, que tem seus objetivos, suas intencionalidades e seus pressupostos com foco em seu ofício. Então, no entendimento dos professores, aprender para ensinar significa, na prática, vivenciar experiências que possibilitem ao professorado repensar seus saberes-fazeres, de maneira que estes possam ser aprendidos na prática. Isso nos permite inferir que, ao expressar esse saber-fazer com o corpo, produzimos um conhecimento traduzido em uma linguagem corporal que se ampara nas experiências vivenciadas e na relação que o sujeito estabelece consigo e com seus pares (ARROYO, 2000; CHARLOT, 2000).

Os saberes-fazeres docentes guardados dentro de suas caixas de ferramentas carecem de ser valorizados e investigados no decorrer do processo formativo, de modo a identificar onde se dá o aprendizado. Essas trocas remetem à possibilidade de intervenção, ação e produção em cada situação nova, ou inesperada, pois, embora não sejam as mesmas, essas trocas parecem possibilitar que se escolham as "ferramentas" mais apropriadas como alternativas prévias (ARROYO, 2000; TARDIF, 2000a).

\section{Síntese propositiva}

As interpretações dessa experiência formativa permitem-nos avaliar que emergem o que denominamos de princípios orientadores do processo formativo, a saber: a) trabalho coletivo e colaborativo; b) saberes e trocas de experiências dos professores; c) ratificação de que os docentes sejam atores e autores do processo; e d) sugestão para aproximações entre as discussões acadêmicas e o "chão da escola".

Tais princípios, autoprojetados pelos docentes no desenvolvimento da referida experiência, não nos pareceram possíveis de serem interpretados de forma isolada, ou seja, desenvolveram-se de maneira imbricada/interligada à realidade da formação continuada e, também, entre si.

Os professores, coletiva e colaborativamente, podem desenvolver instrumentos intelectuais, ou seja, "ferramentas" que facilitariam o mecanismo e o processo formativo contínuo docente. Podem promover a organização de espaço de aprendizagens entre os pares, por meio 
da troca de experiências e partilha de saberes, não se restringindo a uma simples colaboração mútua, mas voltado para um trabalho que possa incorporar princípios coletivos e de colegialidade na cultura profissional docente (IMBERNÓN, 2000; ARROYO, 2000; NÓVOA, 2002; TARDIF, 2002).

\section{Referências}

ARROYO, M. G. Ofício de mestre: imagens e auto-imagens. 6. ed. Petrópolis, Vozes, 2002.

BOGDAN, R.; BIKLEN, S. K. Investigação qualitativa em educação: uma introdução à teoria e aos métodos. Porto, Porto Editora, 1994.

BONDÍA, J. L. Notas sobre a experiência e o saber de experiência. Revista Brasileira da Educação, Rio de Janeiro, Anped, n. 19, jan./fev./mar./abr. 2002.

BRACHT, V; CAPARROZ, F. E. O tempo e o lugar de uma didática da educação física. Revista Brasileira de Ciências e do Esporte, Campinas, v. 28, n. 2, p. 21-37, jan./fev./mar. 2007.

CHARLOT, B. Ensinar a educação física ou ajudar o aluno a aprender o seu corpo-sujeito? In: DANTAS JUNIOR, H. S.; KUHN, R.; RIBEIRO, S. D. D. Educação Física, esporte e sociedade: temas emergentes. São Cristóvão, Editora da UFS, 2009. v. 3, p.231-246.

CHARLOT, B. Da relação com o saber: elementos para uma teoria. Porto Alegre: Artes Médicas Sul, 2000.

CHAUÍ, M.; NOGUEIRA, M. A. O pensamento político e a redemocratização do Brasil. Lua Nova, São Paulo, n. 71, p. 173-228, 2007.

DIAS SOBRINHO, J. Avaliação: políticas educacionais e reformas da educação superior. São Paulo, SP, Cortez, 2003. Disponível em: http://www.scielo.br/pdf/\%0D/es/v25n88/a04v2588.pdf. Acesso em 22 jun. 2017.

DIAS SOBRINHO, J. Avaliação ética e política em função da educação como direito público ou como mercadoria? Educação e Sociedade, Campinas, v. 25, n. 88, p. 703-725, out. 2004. Número especial. Disponível em: http://www.scielo.br/pdf/\%0D/es/v25n88/a04v2588.pdf. Acesso em 23 mar. 2018.

HOFLING, E. de M. Estado e políticas (públicas) sociais. Cad. CEDES [online]. 2001, vol.21, n.55, pp.30-41. Disponível em:

http://dx.doi.org/10.1590/S0101-32622001000300003. Acesso em: 22 ago. 2018.

IMBERNÓN, F. Formação docente e profissional: formar-se para a mudança e a incerteza. São Paulo: Cortez, 2000.

MOLINA NETO, V. A prática dos professores de educação física das escolas públicas de Porto Alegre. Movimento, Porto Alegre, ano V, n. 9, p. 31-46, 1998.

NÓVOA, A. Formação de professores e trabalho pedagógico. Lisboa, Educa, 2002. 
SACRISTÁN, J. G. A avaliação no ensino. In: SACRISTÁN, J. G.; PÉREZ GÓMEZ, A. I. Compreender e transformar o ensino. 4. ed. ArtMed, 1998. p. 295-348.

SARMENTO, M. J. O estudo de caso etnográfico em educação. In: ZAGO, N.; CARVALHO, M. P. de.; VILELA, R. A. T. (Org.) Itinerários de pesquisa: perspectivas qualitativas em Sociologia da Educação. Rio de Janeiro, DP\&A, 2011. p. 137-179.

TARDIF, M. Saberes profissionais dos professores e conhecimentos universitários: elementos para uma epistemologia da prática profissional dos professores e suas conseqüências em relação à formação para o magistério. Revista Brasileira de Educação, São Paulo, n. 13, p. 5-24, jan./fev./mar./abr. 2000a. Disponível em: http://www.joinville.udesc.br/portal/professores/jurema/materiais/RBDE13_05_MAURICE_ TARDIF.pdf. Acesso em: 20 jul. 2017.

TARDIF, M.; RAYMOND, D. Saberes, tempo e aprendizagem do trabalho no magistério. Revista Educação \& Sociedade, Campinas, ano XXI, n. 73, p. 209-244, dez. 2000b. Disponível em: http://www.scielo.br/pdf/\%0D/es/v21n73/4214.pdf. Acesso em: 20 jul. 2017.

TARDIF, M. Saberes docentes e formação profissional. 4. ed. Rio de Janeiro, Vozes, 2002.

Recebido em: $15 / 12 / 2018$

Revisado em: 25/02/2019

Aprovado em: 25/02/2019

Endereço para correspondência:

cacaualeixo@yahoo.com.br

Cláudia Aleixo Alves

Universidade Federal do Espírito Santo, Centro de Educação Física e Desportos.

Av. Fernando Ferrari S/N

Goiabeiras

29000-300 - Vitoria, ES - Brasil 